\title{
Jumping in the deep end: 1970 s structural challenges and their impact for a career in crystallography teaching and research William Clegg ${ }^{1}$ \\ ${ }^{1}$ Chemistry, School of Natural and Environmental Sciences, Newcastle Univ bill.clegg@ncl.ac.uk
}

My very first crystal structure in 1971 was a catalogue of challenges: photographic data collection from very thin plate crystals mounted about two different axes, a triclinic unit cell with two essentially equal axis lengths, twinning, massive absorption effects together with high X-ray fluorescence from the sample, and the discovery of a bug in the structure solution software that prevented automatic Fourier map peak finding. I learnt a huge amount (and lost a lot of sleep) in a few weeks! The remaining structures for my $\mathrm{PhD}$ thesis involved using a new semi-automatic twocircle diffractometer and having to write bespoke data reduction software (having only just learnt how to program), crystals suffering decomposition during data collection, and testing the unreleased first versions of SHELX as well as molecular graphics software that was the forerunner of CCDC's Mercury. These experiences generated a lifelong interest in diffraction data collection methods including developing diffractometer control software, using the first commercial turnkey CCD detector systems, and leading a project to construct and commission the highly successful first synchrotron single-crystal diffraction beamline at Daresbury Laboratory. They also provided the foundation of crystallographic knowledge and understanding that has enabled me to contribute to many international training courses and produce four popular textbooks. This year marks a half-century of this career, in which early lessons have reappeared in new forms with fresh applications. 